\title{
Service-Learning Case Study in Heat Transfer
}

\author{
Nihad Dukhan \\ Associate Professor, Department of Mechanical Engineering \\ University of Detroit Mercy \\ 4001 W. McNichols Rd. \\ Detroit, MI 48221 \\ nihad.dukhan@udmercy.edu \\ Mark R. Schumack \\ Professor, Department of Mechanical Engineering \\ University of Detroit Mercy \\ 4001 W. McNichols Rd. \\ Detroit, MI 48221 \\ schumamr@udmercy.edu \\ John J. Daniels \\ Director, Leadership Development Institute \\ University of Detroit Mercy \\ 4001 W. McNichols Rd. \\ Detroit, MI 48221 \\ danieljj@udmercy.edu \\ Michael G. Jenkins \\ Professor and Chair, Department of Mechanical Engineering \\ University of Detroit Mercy \\ 4001 W. McNichols Rd. \\ Detroit, MI 48221
}

\begin{abstract}
This paper describes the implementation and the impact of a service-learning project in a heat transfer course for undergraduate engineering students. The students visited low-income households in the Detroit area and installed insulation materials on doors and windows thereby conserving energy and reducing heating costs during the cold months. The students collected information about the materials, dimensions, and relevant engineering parameters. They used the information to calculate the resulting dollar amount of energy savings. There were interactions with a university office in charge of assisting the faculty in using service learning by developing course-relevant community-service projects. There was collaboration with a nonprofit organization that promotes the development of resource efficient homes through training and technical assistance. Data were first gathered about the students' awareness and attitudes regarding the relationship between engineering work and society. Students rated themselves in leadership attributes such as empathy, awareness, conceptualization, and the community, and also in social justice interests such as the dignity of the human person, the common good, rights, responsibilities and poverty. After conducting the project, they reflected on their experience. Analysis of the students' responses clearly showed that they became more aware and perceptive of their role as engineers in a societal context.
\end{abstract}

Index Terms - heat transfer, mechanical engineering, reflection, service learning 


\section{INTRODUCTION}

Among the many changes introduced in the ABET EC200 criteria ' $3 \mathrm{a}$ ' through ' $3 \mathrm{k}$ ' is outcome ' $h$ ', which addresses the broad education necessary to understand the impact of engineering solutions in an environmental and societal context. ${ }^{i}$ The National Academy of Engineers projects that the years between now (2006) and the year 2020 offer the engineering profession the opportunity to strengthen its leadership role in society. ${ }^{\text {ii }}$

Service learning offers a great opportunity for leadership training and awareness of the societal context of engineering through community service. The National Service Learning Clearinghouse defines service learning as "a teaching and learning strategy that integrates meaningful community service with instruction and reflection to enrich the learning experience, teach civic responsibility, and strengthen communities." iii

A service-learning project was undertaken by undergraduate mechanical engineering students in their heat transfer course at the University of Detroit Mercy (UDM). The service learning assignment was implemented for the first time in the spring semester of the 2004-2005 academic year, and then again in the spring of 2005-2006. A total of 35 students participated in the assignment.

There were three noteworthy factors that contributed to the success of the service-learning process, in addition to the collaboration among the involved parties, as explained below. One of the objectives of the bachelor of mechanical engineering program at UDM is to produce engineers who 1) are aware of how their role as technical professionals and leaders affect the wider human community, 2) serve not only as employees or employers but also as sociallyconscious citizens and 3) are motivated by moral principles in their professional and personal lives.

The mission statement of UDM declares that the university "is a Catholic university in the Jesuit and Mercy traditions that exists to provide excellent student-centered undergraduate and graduate education in an urban context." Such education seeks "to integrate the intellectual, spiritual, ethical and social developments of students." Additionally, the vision statement of the university says that it is "distinguished by graduates who lead and serve in their communities." Service-learning projects in general help fulfill UDM's mission, and they receive full support from the administration.

The Leadership Development Institute (LDI) of UDM is in charge of developing leadership and community service programs, as well as working closely and forming partnerships with various local organizations performing similar work. The LDI was established with the help of the Kellogg Foundation in 1995 to provide students with awareness of urban concerns and reflection on them, with leadership skills, and relationships with diverse staff, faculty, alumni, and community mentors to develop solution strategies. One of the goals of LDI is to help students embody the UDM's vision statement. ${ }^{\text {iv }}$ Currently there are 63 service-learning courses enrolling 1300 students annually at UDM. Another 800 students engage in unpaid community service through other LDI programs, and 500 more through other UDM programs.

The WARM Training Center is a non-profit organization that has been working in the Detroit area on issues related to affordable housing for almost 20 years. It promotes the development of resource-efficient, affordable, healthy homes and communities through education, training and technical assistance. In the past ten years WARM has increasingly been a technical assistance resource to nonprofit organizations building and rehabilitating affordable housing. WARM's other main thrust has been educating residents on home repairs, energy matters, and other issues 
related to sustainability. It has several construction specialists on staff with decades of residential building experience, and in designing and implementing educational services that are energy related. One of the unique aspects of WARM is its close association with community-based and faith-based housing organizations in the Detroit metropolitan area. It brings together lenders, governmental agencies, and non-profit housing groups to explore solutions to a variety of community development issues. WARM is a member of the Michigan Energy Network, a coalition of non-profit organizations and university representatives involved in sustainability issues.

The collaboration among the above parties ensured the success of the service-learning experience. This paper describes in some detail the service-learning project, the interactions among the involved parties and the logistics of implementation, the assessment process and the impact on the students' attitudes and awareness of their future profession and its impact on society. The logistics for conducting the service are described first, followed by a presentation of the heat transfer computations and their assumptions. The assessment, data collection and analysis are then given, including a description of the multiple surveys completed by the students.

\section{LOGISTICS}

The service learning component was declared in the syllabus of the heat transfer course and was worth $5 \%$ of the final grade. WARM has a program that teaches homeowners how to save on fuel and electricity bills by installing plastic storm windows, rope caulk, and door sweeps. Most residents perform the installations themselves, but for those who needed assistance, students did the work. The WARM coordinator provided contact information and possible dates to the heat transfer instructor, who passed the information to student teams of two. The students would call the residents to set up specific appointment times for the visits, and then went to the homes to install the materials identified by WARM energy counselors. Each visit lasted approximately two to three hours. Students noted window type (single or double glazed) and took window and door measurements for calculating decreases in heat loss due to modifications.

Before the actual work was done, the students listened to a forty-minute presentation by the LDI director. In this presentation, the speaker touched on the university's mission and vision, especially the parts that were related to the service component. The speaker explained the steps of introducing positive change as seeing, feeling, helping, and finally fostering lasting change. The presentation also defined service learning and its benefits in meeting or exceeding the course technical learning objectives. The service learning experience was put in the perspective of the Kolb’s Learning Cycle, as shown in Fig. 1.

The LDI also had the students fill out two different surveys: Service Learning Form 1 (SL1) shown as Appendix I, and Service Learning Form 4 (SL4) shown as Appendix II. The first form included registration information about the course and the student, and collected information about the student's leadership evaluation and social justice interests. Form SL4 asked the same questions as form SL1, but was completed after the service learning experience. The speaker also discussed the essential components of service learning:

1. Analysis of community need: identification of real service that students can provide, by responding to unmet needs;

2. Preparation of students for the experience, capable of serving and open to its potential for transformation; 
3. Performance of direct service, in which they are able to experience the humanity of the person served;

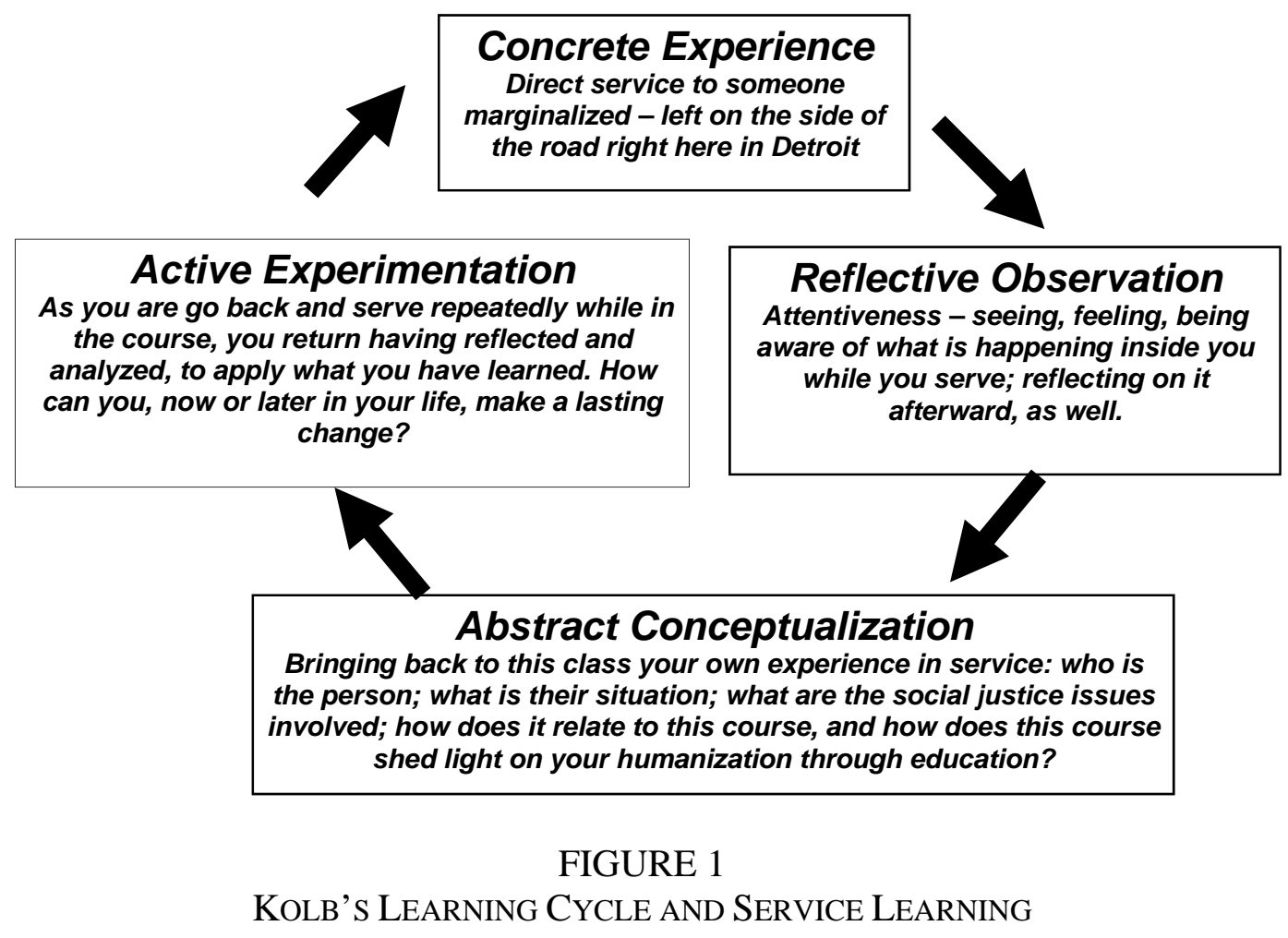

4. Reflection as a continuous state of mind, through examining, journaling, etc.;

5. Integration of the experience with other sources of learning in the course;

6. Evaluation of the impact of the service on their learning.

These are inline with the Corporation on National and Community Service, which identifies three general aspects of service learning projects: preparation (setting objectives, planning projects), performing the service, and reflection. ${ }^{\text {vi }}$

In addition to the input from LDI, one senior person from WARM addressed the class for about forty minutes. The speaker discussed WARM's mission and the scope of work the organization was involved in, and talked about energy conservation and alternative energy initiatives at WARM. He then addressed the specific service-learning experience and informed the students of their tasks. Finally, the speaker presented the actual materials that the students were to install at the homes, and gave them a brief demonstration of how to install them. As a meaningful token of appreciation, each student was given an energy-saving light bulb.

\section{The Heat Transfer Component}

Four of the declared outcomes of the heat transfer course at UDM related to this service-learning project are to

1. identify heat transfer modes for common engineering situations,

2. work with simple relationships for 1-D conduction, convection, and radiation,

3. apply the energy balance equation to heat transfer problems, and to 
4. apply the thermal resistance method to calculate the rate for heat transfer through plane walls and radial systems.

These outcomes are directly linked to at least two of the general mechanical engineering program's objectives based on ABET's criteria:

a) an ability to apply knowledge of math, science and engineering principles to manufacturing, thermal and mechanical systems.

b) an ability to identify, formulate, and solve mechanical engineering problems.

The two technical objectives of the service-learning project were to:

- give students experience with practical applications of heat transfer,

- to impress students with the importance of energy conservation.

The first of these objectives is related to all of the four outcomes of the course, while the other is related to the outcome 4 in the sense that the students converted the reduction in heat loss to an actual savings in actual dollars.

For the service-learning project, the heat transfer calculations fell into two categories: infiltration through cracks and transmission losses through windows. Students followed the standard methodologies outlined in ASHRAE Fundamentals, ${ }^{\text {vii }}$ and in their text book. ${ }^{\text {viii }}$

For crack infiltration, the following relationship was used for the rate of heat loss:

$$
\dot{Q}_{\text {infil }}=\rho \dot{V} c_{p}\left(T_{i}-T_{o}\right)
$$

where $\dot{Q}_{\text {infil }}$ is the heat transfer rate, $\rho$ is the density of air, $\dot{V}$ is the volumetric flow rate, which is determined using volumetric flow rate per unit length data for door and window cracks, $c_{p}$ is the specific heat of air at constant pressure, $T_{i}$ is the temperature inside the house and $T_{o}$ is the outside ambient temperature. Infiltration losses through window cracks were assumed to be eliminated by rope caulk, while door crack infiltration was assumed to be halved (consistent with ASHRAE recommendations). While the benefit of reducing or eliminating cracks is increased thermal comfort, lack of infiltration can cause increased level of indoor air pollution since little or no fresh air enters the house.

For transmission heat transfer loss, which accounts for the inside and outside convection, conduction in the glass and plastic and radiation in the air gap, the following relationship was used:

$$
\dot{Q}_{\text {trans }}=\frac{T_{i}-T_{o}}{R_{\text {tot }}}
$$

where $\dot{Q}_{\text {trans }}$ the heat transfer rate and $R_{\text {tot }}$ is the total thermal resistance given by

$$
\left.\left.R_{\text {tot }}=\frac{1}{h_{i} A}+\frac{L}{k A}\right)_{\text {plastic }}+\frac{R_{s}^{\prime \prime}}{A}+\frac{L}{k A}\right)_{\text {glass }}+\frac{1}{h_{o} A}
$$


where $h_{i}$ and $h_{o}$ are the inside and outside convection heat transfer coefficients, respectively, $L$ is the thickness of the glass window, $A$ is the surface area of the window perpendicular to the heat transfer direction, $\mathrm{k}$ is the thermal conductivity and $R_{s}$ " is the unit thermal resistance for confined airspaces as given in ASHRAE Fundamentals. The thermal resistance $R_{s}$ " accounts for the insulating effect of the airspace between the plastic storm window and the glass, and includes the effects of both convection and radiation between the plane surfaces. For the pre-modification heat loss, the plastic conduction and airspace resistance terms are set to zero. All the homes visited were fitted with single-pane windows.

In order to estimate natural gas cost savings, students used the following formula relating the rate of heat loss reduction to natural gas volume usage rate reduction:

$$
\Delta \dot{V}=\frac{\Delta \dot{Q}}{\eta h_{v}}
$$

where $\Delta \dot{V}$ is the natural gas volume rate reduction, $\Delta \dot{Q}$ the rate of heat loss reduction, $\eta$ is the combustion efficiency of the furnace and $h_{v}$ is the heating value of natural gas.

The students wrote reports describing their modifications and estimated savings (Table 1). The following assumptions were used in the above heat transfer calculations:

1. Outside temperature $=0{ }^{\circ} \mathrm{C}\left(32^{\circ} \mathrm{F}\right)$

2. Inside temperature estimated by students during visit

3. Installation of door sweeps, caulk, and plastic decreased infiltration heat loss by half

4. Heat source: natural gas

5. Gas cost $=\$ 0.29 / \mathrm{m}^{3}$ ( $\$ 0.83 / \mathrm{ccf}$ ), where the unit ccf means 100 cubic feet, an unit commonly used in gas bills. Using a heating value of natural gas of $38,500 \mathrm{~kJ} / \mathrm{m}^{3}$, the gas cost can be expressed as $\$ 7.53 / \mathrm{GJ}$.

6. Furnace efficiency $=0.7$

7. Wind speed $=24 \mathrm{~km} / \mathrm{h}(15 \mathrm{mph})$

By installing the actual insulation materials, taking the necessary measurements and performing the above calculations and, the two technical objectives for this service-learning project were satisfied.

TABLE 1

CALCULATION RESULTS

\begin{tabular}{lll}
\hline Residence & Modifications & Savings per month \\
\hline 1 & Installed 1 door sweep, taped 3 glass cracks & $\$ 31.67$ \\
2 & Installed 1 door sweep, taped 1 glass crack, caulked 2 & $\$ 44.70$ \\
3 & windows, installed plastic over 3 windows & $\$ 33.61$ \\
4 & Caulked 8 windows, installed plastic over 6 windows & $\$ 28.48$ \\
5 & Caulked 2 windows, installed plastic over 7 windows & $\$ 27.35$ \\
6 & Installed 4 door sweeps, installed plastic over 1 window & $\$ 16.41$ \\
7 & Installed plastic over 3 windows & $\$ 15.69$ \\
8 & Caulked 2 windows, installed plastic over 3 windows & $\$ 25.00$
\end{tabular}




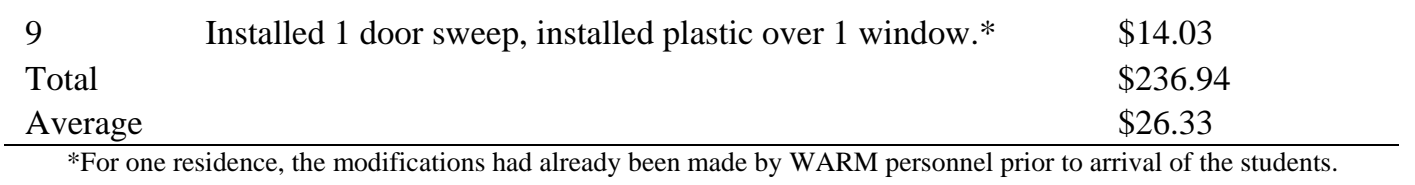

The average time taken by a team of two students to install the materials was about two hours. To get an approximate estimate of the return on the time invested, assuming the current federal minimum wage of $\$ 7.25$ per hour, the time investment is valued at $\$ 14.50$. Assuming that the average cold season the Detroit area last about six months of the year, the total savings comes out to be $\$ 789.9$ for five years, which is an attractive rate of return.

Other advantages of this project include a reduction in natural gas consumption, which translates to reduction is harmful emissions and urban pollution. These effects can become significant if such project and similar projects are conducted on a wider segment of society in many urban centers, can possible contribute to easing the national energy issues.

\section{Assessment AND Data Analysis}

Before conducting the service, the students filled out a questionnaire to gauge their self awareness and attitudes regarding the impact of engineering work on society. Students were asked to rate their competence in a number of leadership qualities and their level of interest in social justice issues. The leadership qualities included empathy, awareness, conceptualization, and the community; while the social justice issues included the dignity of the human person, the common good, rights, responsibilities and poverty. The full questionnaire is reproduced as Appendix I and is referred to as service learning form 1 (SL1).

After completing the service, the students filled out a post-service questionnaire, which is shown as Appendix II and referred to as form SL4. In this form, the students addressed the same items of SL1, but from two perspectives: what they felt their competence and level of interest was before the course, and what they felt about their competence and level of interest at the end. Additionally, students were to judge the quality of the service in terms of its engineering education value and its contribution to their appreciation for social justice issues.

The following figures illustrate the impact on the students' attitudes. Only seventeen students completed the assessment forms. Figure 2 compares the responses of the students to improvements noted in the areas of persuasion as opposed to positional authority ( $3.53 \pm 0.87$ before vs. $4.14 \pm 0.66$ after), conceptualization by thinking in a broad-based manner (3.82 \pm 0.70 before vs. $4.36 \pm 0.50$ after) and building the community (3.06 \pm 1.03 before vs. $3.79 \pm 0.98$ after). The first number represents a measured value and the second represent the standard deviation. Note that in addition to notable improvements in the mean response between before and after, there are improvements in consistency of response as indicated by decreases in standard deviations from the before to the after. Some of the other attitudes showed small to moderate improvement. Four of the attitudes showed small declines. These were rights and responsibilities (the belief that all people have the fundamental right to life, food, shelter, health care, education and employment) ( $4.41 \pm 0.80$ before vs. $4.29 \pm 0.73$ after), dignity of work (the belief that all people have the fundamental right to decent and productive work and fair wages) (4.29 \pm 0.92 before vs. $4.07 \pm 0.27$ after), solidarity (thinking that all people are one human family and that all must work for justice) ( $4.06 \pm 1.09$ before vs. $3.93 \pm 0.62$ after), and finally care for God's creation (the understanding that all goods of the earth are gifts from God and that the humans are stewards and trustees not mere consumers) ( $4.41 \pm 0.80$ before vs. $4.14 \pm 0.54$ after). The decline 
in these four items was further investigated and proved to be a false indicator, and that it had been due to lack of deep reflection and awareness, which led to self-misevaluation by the students. This point is illustrated further by considering Fig. 3.

In form SL4, the students were asked the same list of questions as those of SL1, in the same order and wording. They were asked to provide their attitudes before and after the service. This, of course, included answering the questions that had been answered in the SL1, which had been completed before the service. The before-the-service responses in SL4 showed significant difference when compared to their counterparts in SL1. Figure 3 shows the results of SL4, which strongly suggests that providing the service caused the students to reconsider their initial responses and increased their awareness of their own attitudes. Unlike Fig. 2, Fig. 3 shows that the improvement covered the whole spectrum of attitudes that was investigated by surveys. It is worth noting that the listening and empathy categories improved substantially, while other attitudes show significant improvement.

To assess the educational impact of the service learning project, form SL4 included one question addressing the extent that the service helped in learning the course technical materials. Another question was about the impact on the students' growth as persons engaged in making the society more just and compassionate. A third question asked about the teacher's engagement, while the last question asked the students to what extent the service experience allowed them a direct contact with the poor. The responses to these four questions are shown graphically in Fig. 4 , with a rating of 1 being the lowest and of 5 being the highest. This figure clearly shows that there were advantages in all four areas.

The other service-type objectives for this project were:

- to expose students to low-income living conditions

- to promote understanding of the importance of community service

- to give students an awareness of how they can use their engineering knowledge to serve the disadvantaged

The first objective was satisfied through the fact that each student went on a home visit to a resident who had applied for energy assistance. The extent to which the last two objectives were satisfied is more difficult to quantify, but student feedback indicates that this was a positive, eyeopening experience for most participants.

Each student was required to write a reflection on his or her experience. In general, the reflections were very honest and thorough in describing the students' experiences. Many of the students who went into the assignment with some apprehension came away feeling very good 


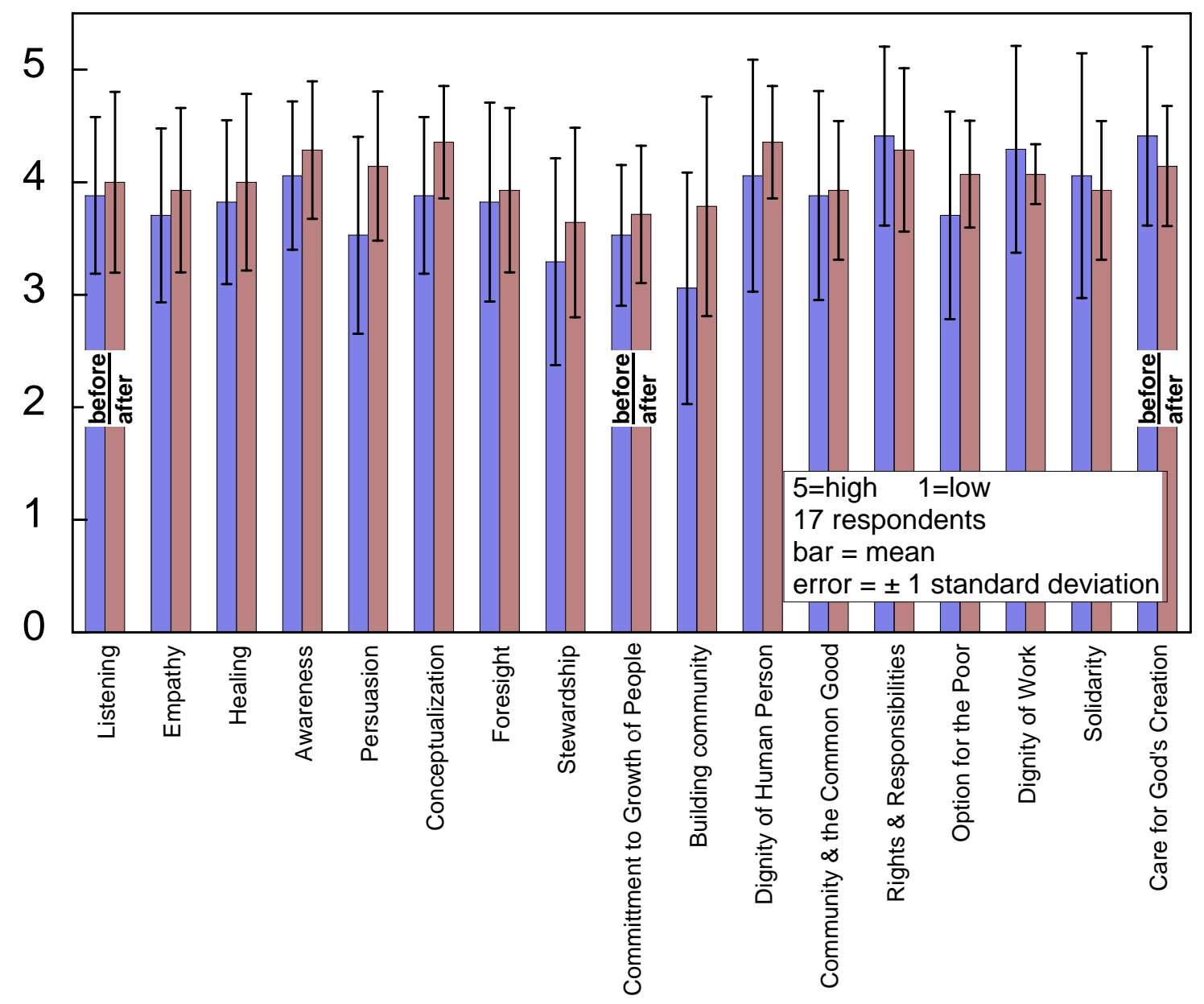

FIGURE 2

COMPARISONS OF THE STUDENTS’ RESPONSES BEFORE (SL1) AND AFTER (SL4) THE SERVICELEARNING EXPERIENCE 


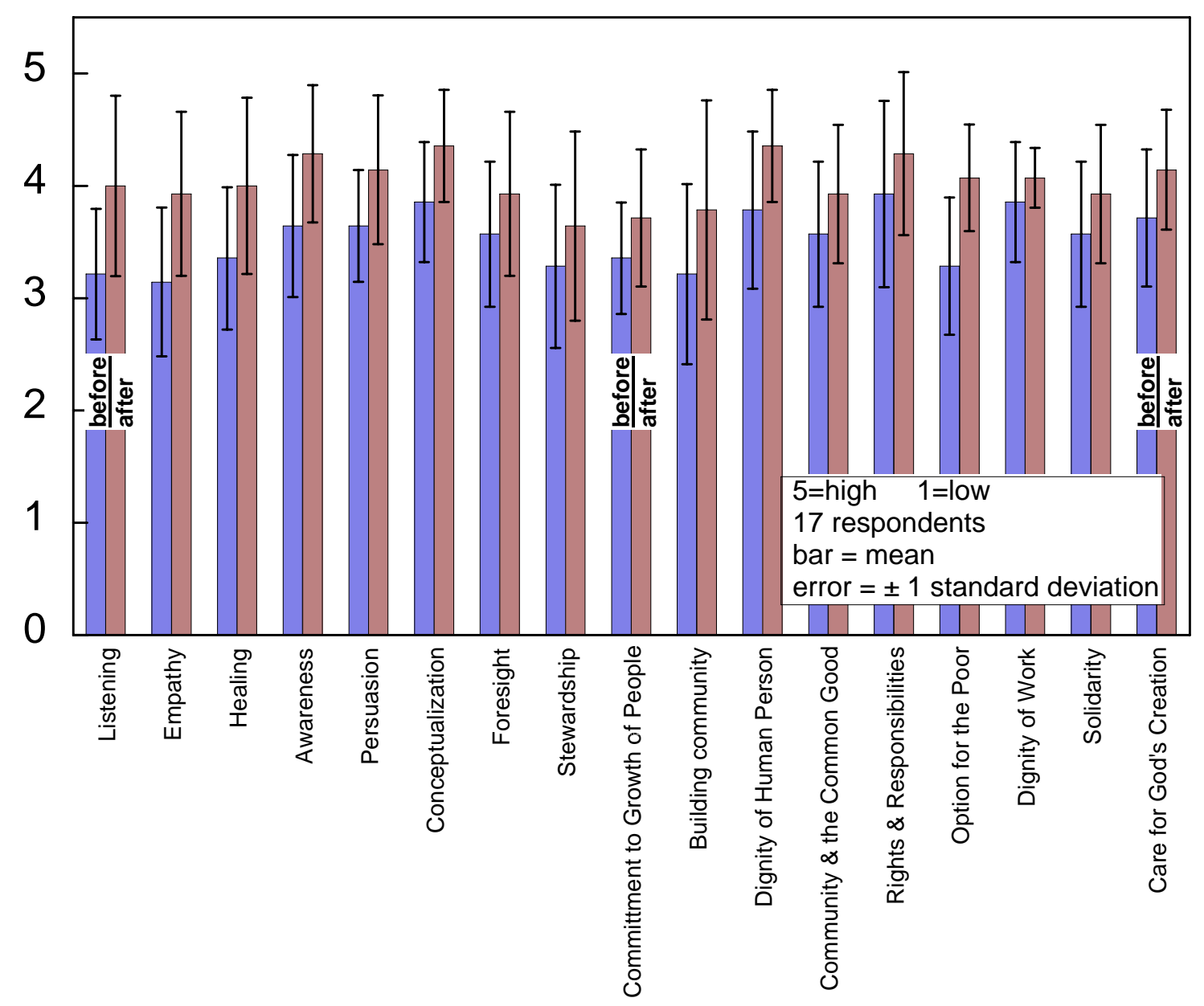

FIGURE 3

COMPARISONS OF THE STUDENTS’ RESPONSES BEFORE AND AFTER THE SERVICE-LEARNING EXPERIENCE BASED ON SL4 ONLY

about the experience: about helping someone in a tangible, valuable way, and about relating to people outside their normal social circles. Some samples of the students' comments are reproduced below.

- "Before I started this assignment I was nervous. I was not sure what type of place I would be going to. I just hoped that the people I was trying to help would be nice. Luckily for me they were very hospitable and more than happy to have us there."

- "Before I began this WARM project action I must say I was not very enthusiastic . . . after installing the material to allow the home to be more efficient, I am happy I did it."

- "As my goal, I would like to move into such a neighborhood with the hopes of changing it for the better."

- "I will admit I let stereotypes affect how I felt about the assignment ... I was initially afraid that we were going to be placed to work in a home where the people were abusing the system and using us ... however, Mr. Young was not one of these people ... I was actually glad that I was able to go and help him out.” 


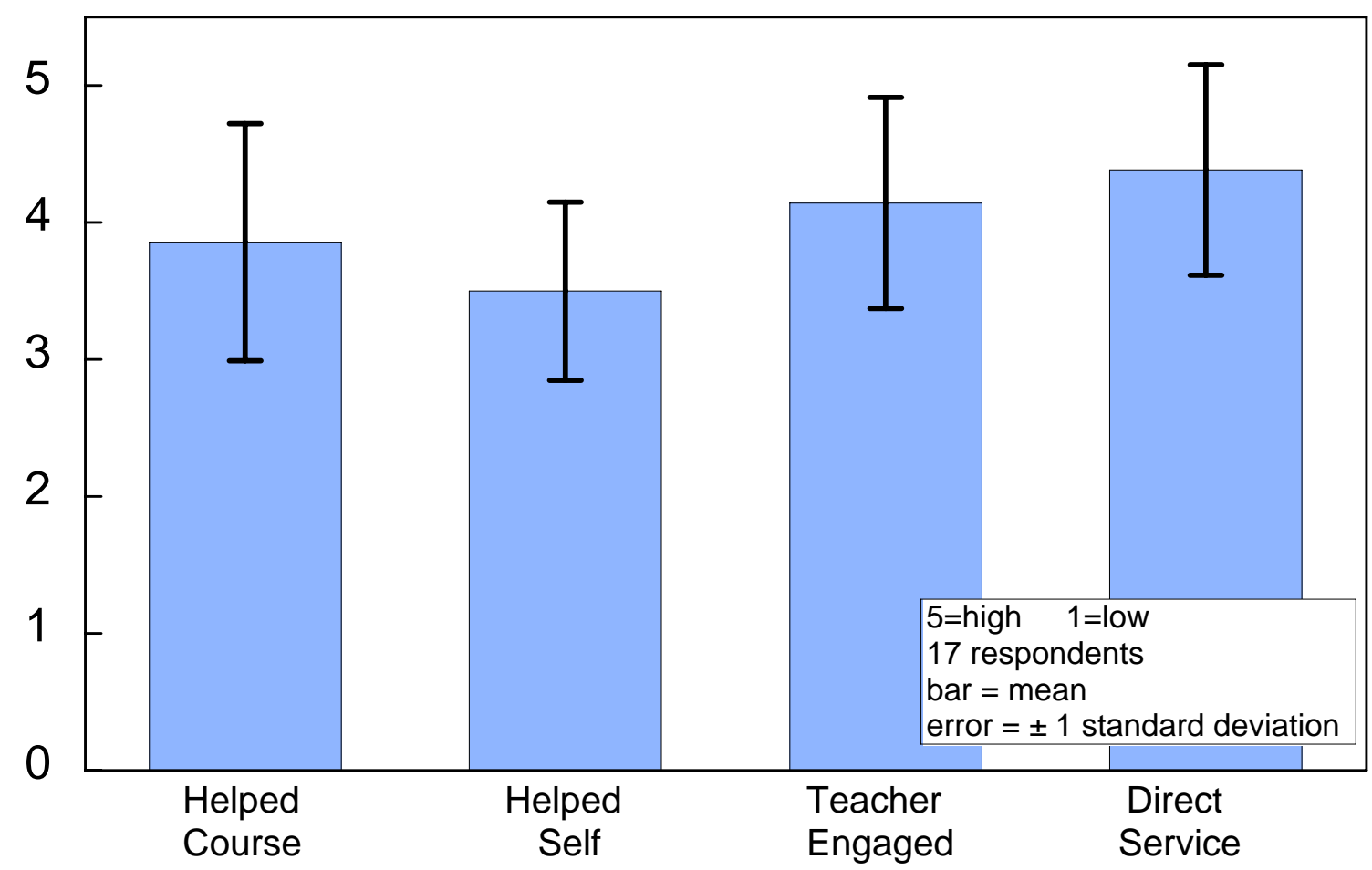

FIGURE 4

Other AdVANTAgES OF THE SERVICE-LEARNING EXPERIENCE

\section{SUMMARY AND CONCLUSION}

A service learning project in an engineering heat transfer course was described. Thirty-five undergraduate students were asked to install insulation materials on doors and windows in low-income neighborhoods. In addition, the students had to compute the heat loss reduction due to the new insulation and convert that to monetary savings in heating bills. As an incentive, the students were given some extra points towards their final grade in the course. The impact on seventeen of the students' attitudes regarding leadership and social justice issues was illustrated. Using surveys addressing the different issues, the impact on the students' attitudes was substantial, especially in listening and empathy. The experience had a positive impact on other leadership and social justice areas, as well as students' self awareness of their own attitudes. The heat transfer learning outcomes directly related to the service was satisfied. The service project was effective in partially satisfying the ABET EC2000 criterion ' $3 \mathrm{~h}$ ' which is the broad education necessary to understand the impact of engineering solutions in an environmental and societal context; and it was in-line with new pedagogies in engineering education, which emphasize learning-by-doing and relating technical topics to real-life situations. This project can serve as a methodology for applying service learning components in other engineering courses. Meaningful parallels can be drawn between heat transfer and other disciplines within engineering to facilitate this. In addition, 
International Journal for Service Learning in Engineering

Vol. 2, No. 1, pp. 1-15, Spring 2007

ISSN 1555-9033

an appropriate community service can be found that is directly linked to one or more of the technical content areas of the course. 


\section{APPENDIX I}

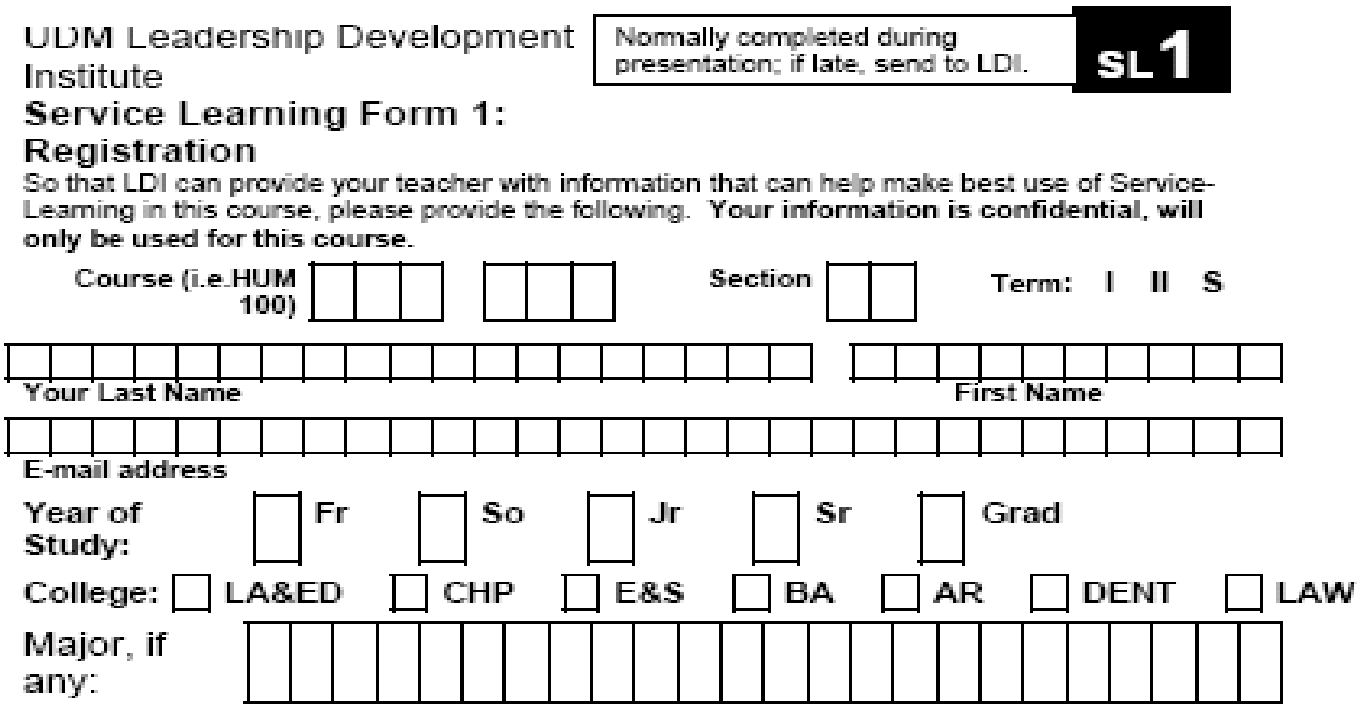

3. Your Leadership Self-evaluation: Service-Leaming is not just a service project. It is the use of service to help develop graduates who lead and serve in their communities.

Please rate your Current level of competence in each from 1(low) to 5 (high)

[ ] Listening: listening intently to others, getting in touch with one's own inner voice.

[ ] Empathy: understanding and empathizing with others.

[ ] Healing: care for yourself and your relationship to others

[ ] Awareness: General awareness, self-awareness, ethics, power and values.

[ ] Persuasion: use of persuasion rather than positional authority, consensus-building

[ ] Conceptualization: thinking to encompass the broader-based "big picture-"

[ ] Foresight: the ability to foresee the likely outcome of a situation

[ ] Stewardship: a commitment to serving the needs of others

[ ] Commitment to the growth of people: nurturing growth of employees and colleagues

[ ] Building community: developing and modeling interdependence

4. Your Social Justice Issue Interest: In your Service project and in your studies and career, the following are areas in which you can have impact, just by the way you do what you do. Please rate your interest in each issue from 1(low) to 5 (high)

[ ] Dignity of the Human Person: All people are sacred. People do not lose dignity because of disab ty. poverty. age, lack of success, or race.

[ ] Community and the Common Good: We realize our dignity and rights in relationship with others, in community. We are called to respect creation, be good stewards of the earth \& each other.

[ ] Rights and Responsibilities: People have a fundamental right to life, food, shelter. health care, education and employment. Corresponding to these is the duty to work for the common good.

[ ] Option for the Poor: The moral test of a society is how it treats its most vulnerable members. The poor have the most urgent moral claim on the conscience of the nation, and our good efforts

[ ] Dignity of Work: People have a right to decent and productive work, fair wages, private property and economic initiative. The economy exists to serve people, not the other way around.

[ ] Solidarity: We are one human family. Our responsibities to each other cross national. racial, economic and ideological differences. We are called to work globally for justice.

[ ] Care for God's Creation: The goods of the earth are gifts from God. We have a responsibility to care for these goods as stewards and trustees, not as mere consumers and users.

5. Leadership-In-Service Medallion program: Would you like LDI to include you in e-mail about leadership workshops, service projects, and reflections leading to the Medalion? Service hours and reflection in this class can be applied to the totals. If interested, $X$ this box: [ ] 
UDM Leadership Development Institute

APPENDIX II

Service Learning Form 4: Evaluation

So that we can evaluate the effectiveness of our program, please provide thoughtful response to the following questions. Your information is confidential, will only be used for program evaluation purposes.
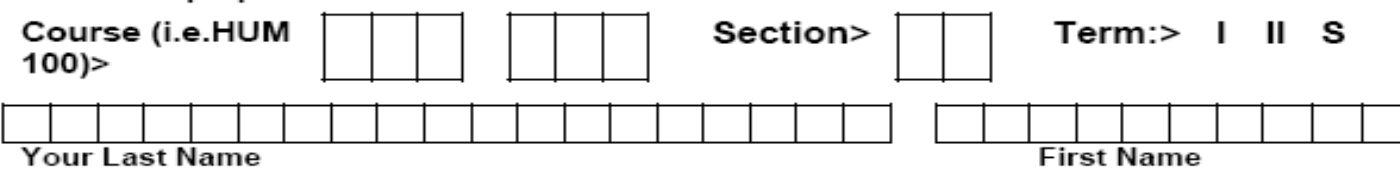

1. Your Leadership Self-evaluation, before this course and now: Please rate your level of competence BEFORE this course (column B) and NOW (column N) in each item below, from 1(low) to 5 (high)

Berore Now

[ ] [ ] Listening: listening intently to others, getting in touch with one's own inner voice.

[ ] [ ] Empathy: understanding and empathizing with others.

[ ] [ ] Healing: care for yourself self and your relationship to others

[ ] [ ] Awareness: General awareness, self-awareness, ethics, power and values

[ ] [ ] Persuasion: use of persuasion rather than positional authority; consensusbuilding

[ ] [ ] Conceptualization: thinking to encompass the broader-based "big picture"

[ ] [ ] Foresight: the ability to foresee the likely outcome of a situation

[ ] [ ] Stewardship: a commitment to serving the needs of others

[ ] [ ] Commitment to the growth of people: nurturing growth of employees and colleagues

[ ] [ ] Building community: developing and modeling interdependence

2. Your Social Justice Issue Interest, before this course and now: Please rate your level of concern BEFORE this course (column B) and NOW (column N) in each item below, from 1(low) to 5 (high)

Berore Now

[ ] [ ] Dignity of the Human Person: All people are sacred. People do not lose dignity because of disability, poverty, age, lack of success, or race.

[ ] [ ] Community and the Common Good: We realize our dignity and rights in relationship with others, in community. We are called to respect creation, be good stewards of the earth \& each other.

[ ] [ ] Rights and Responsibilities: People have a fundamental right to life, food, shelter, health care, education and employment. Corresponding to these is the duty to work for the common good

[ ] [ ] Option for the Poor: The moral test of a society is how it treats its most vulnerable members. The poor have the most urgent moral claim on the conscience of the nation, and our good efforts

[ ] [ ] Dignity of Work: People have a right to decent and productive work, fair wages, private property and economic initiative. The economy exists to serve people, not the other way around.

[ ] [ ] Solidarity: We are one human family. Our responsibilities to each other cross national, racial, economic and ideological differences. We are called to work globally for justice.

[ ] [ ] Care for God's Creation: The goods of the earth are gifts from God. We have a responsibility to care for these goods as stewards and trustees, not as mere consumers and users.

3. How many hours of Community Service did you perform for this course?

4. If you did perform service, to what extent did it help you learn the material of this course? Please score from 1 (low) to 5 (high) [ ]

5. If you did perform service, to what extent did it help you grow in your own sense of worth as a person engaged in making our society more just and compassionate?

$$
1 \text { (low) to } 5 \text { (high) [ ] }
$$

6. To what extent did the teacher engage service experience in the teaching of this course? Please score from 1 (low) to 5 (high) [ ] 7. If you did perform service, to what extent did it allow you to have DIRECT contact and communication with the poor or marginalized? 1 (low) to 5 (high) [ ] 
${ }^{\mathrm{i}}$ The Accreditation Board for Engineering and Technology (ABET): Criteria for Accrediting Engineering Programs, Baltimore, MD, Nov. 1, 2004, see also www.abet.org.

ii The National Academy of Engineering, “The Engineer of 2020: Visions of Engineering in the New Century," National Academic P, Washington D.C., 2004.

iii www.servicelearning.org, accessed May 12, 2006.

iv John J. Daniels, “Ignatius, Catherine McAuley, and the Good Samaritan: A Leadership Program Finds Sustainability in Its Spirit,” in Connections the AJCU Magazine November, 2003.

vwww.warmtraining.org, accessed May 12, 2006.

${ }^{v i}$ www.compact.org/faqs/s-ldefinitions.html, accessed May 12, 2006.

vii American Society of Heating Ventilating and Air-conditioning Engineers, ASHRAE Handbook, 1981

Fundamentals, Atlanta, GA, Ch. 22, Section 22.8.

${ }^{\text {viii }}$ Yonus A. Cengel, Heat Transfer: A Practical Approach (2 ${ }^{\text {nd }}$ Ed., McGraw-Hill, New York, 2003), $129-133$. 